\title{
IMAGENS DA CIDADE: memória coletiva em londrina
}

\author{
Ana Cleide Chiarotti Cesário* \\ Ana Maria Chiarotti de Almeida** \\ Deise Maia***
}

\begin{abstract}
*Prof ${ }^{a}$. de Ciência Política no Departamento de Ciências Sociais da UEL.
**Prof ${ }^{a}$. de Sociologia no Departamento de Ciências Sociais da UEL ***Prof ${ }^{\text {. }}$ de Antropologia no Departamento de Ciências Sociais da UEL
\end{abstract}

O presente artigo, além de apresentar as experiências de um projeto de pesquisa e extensão, desenvolvido por um grupo interdisciplinar de docentes e acadêmicos da Universidade Estadual de Londrina das diferentes áreas do conhecimento (Antropologia, Arquitetura, Ciência Política, História e Sociologia), discute aspectos teóricos-metodológicos importantes que envolvem as ações de política cultural, bem como os trabalhos com o Patrimônio Cultural na região norteparanaense, especialmente, na cidade de Londrina. Nesse sentido, emergem discussões importantes acerca de categorias teóricas como cultura, patrimônio, preservação, memória, representações, imaginário, identidade, aliadas à investigação de campo e à utilização de procedimentos metodológicos, que contemplam tanto o estudo do cotidiano quanto a utilização da história oral, e que estão sendo, atualmente, objetos de novas reflexões, a exemplo do Projeto de Pesquisa: "Londrina - imagens da cidade", desenvolvido pelas autoras deste trabalho.

Palavras-chave: cultura, patrimônio cultural, preservação, memória coletiva, imaginário, representações, identidade.

\section{AS EXPERIÊNCIAS DE UM PROJETO DE PESQUISA}

$\mathrm{O}$ Inventário e Proteção do Acervo Cultural de Londrina, IPAC/Lda. surgiu em 1985 como um projeto de pesquisa e extensão voltado à coletividade. Procurou encaminhar ações de política cultural, estabelecendo relações de aliança com a população, a fim de reconstituir a memória coletiva de grupos sociais no "Paraná Moderno".
Propôs, neste sentido, uma "política de conhecimento" ao reunir vários profissionais ${ }^{1}$ que, com diferentes ângulos de observação e análise, bem como procedimentos de pesquisa, preocuparam-se em compreender as representações de valores e tradições "coladas" às práticas sociais de diferentes protagonistas sociais, para implementar ações de intervenção e reconhecer bens materiais e simbólicos que constituem o Patrimônio Cultural da região norteparanaense.

Um trabalho com estas características, desde o início, elegeu o "depoimento", a "história de

\footnotetext{
${ }^{1}$ A equipe interdisciplinar é constituida por profissionais da UEL, e acadêmicos, das diferentes áreas do conhecimento: Antropologia, Arquitetura, Ciência Política, História e Sociologia.
} 
vida" e a "entrevista", (técnicas oriundas de Antropologia, Sociologia e Ciência Política) como recursos de investigação. Houve, portanto, uma concordância de metodologia de pesquisa de campo com os historiadores do projeto que, de seu lado, percebiam a importância de instrumentos de registro de informações compatíveis com os caminhos metodológicos já trilhados pela História, quando privilegia depoimentos orais. Ademais, tratava-se de um projeto que nascia na Universidade Estadual de Londrina, onde o Centro de Documentação e Pesquisa Histórica e o Departamento de História foram precursores da história oral do Brasil. O IPAC, já na sua origem, embora com uma forte marca antropológica em suas linhas de investigação, contou com a proximidade de historiadores sensíveis às técnicas e recursos de pesquisa que caracterizam a história oral, bem como com dois acervos já constituídos de depoimentos gravados e organizados: o primeiro do $\mathrm{CDPH}$ e o segundo do Museu Histórico de Londrina "Pe. Carlos Weiss" (Órgão Suplementar da Universidade). Desse modo, as gravações e transcrições existentes nestes dois órgãos passaram a ser fontes de pesquisas para o IPAC.

Os trabalhos de campo desenvolvidos pelo IPAC combinam as técnicas já citadas com as observações direta e participante, assumindo a intersubjetividade que permeia a relação investigador/investigado, buscando os lugares e os tempos da produção da fala, bem como os significados a partir de relações sociais tecidas por diferentes atores.

Num primeiro momento, o IPAC/Lda. voltou a atenção para um espaço urbano londrinense considerado como um dos núcleos mais antigos: a Vila Casoni. Esta última evoca ora aspectos de Londrina antiga, ora expressa a fisionomia de um bairro de camadas populares. Sua paisagem apresenta a persistência do plano horizontal, em contraste com o núcleo central e o processo de verticalização; uma expressiva quantidade de exemplares de casas de madeira no alinhamento das calçadas, um traçado urbano relativamente informe e interações sociais fundamentadas em laços de família, de vizinhança e de parentesco.

Um olhar mais atento para aquele espaço e o envolvimento com os moradores permitiram interpretações de um imaginário da cidade concebido como "abaixo da linha", que traduz um modo de ser e de viver "abaixo", em termos geográficos e no mapa social.

Isso revela uma lógica do sistema de interações sociais que mantém vivas as tradições, baseadas numa matriz simbólica construída no meio rural e redefinida no dia-a-dia do convívio com novo meio, e que, também, faz parte do tecido urbano londrinense. São significados atribuídos à cidade, por atores que fazem uma "leitura" de Londrina a partir das vilas e do bairro Casoni, manifestando as aspirações de participação do processo de urbanização e de um tipo específico de modernização ${ }^{2}$.

Para começar a explicar a dinâmica da região norteparanaense é necessário evocar a Companhia de Terras Norte do Paraná e o projeto dos ingleses que planejaram tanto o meio rural como propuseram diretrizes urbanísticas. Além disso, é preciso estar atento às apropriações e usos dos espaços, quer no passado, em que atores sociais reconstruíram mapas rurais e urbanos, quer no presente, na medida em que esses espaços sofreram alterações ao serem reutilizados por outros agentes que expressam outros significados aos mesmos.

Em continuidade a este trabalho a respeito do Patrimônio Cultural, em 1989, os pesquisadores deste Projeto procuraram interpretar as marcas deixadas pela cafeicultura no Norte do Paraná, considerando tantos os processos de colonização espontânea, quanto dirigida (no campo e na cidade).

Elaboraram, assim, um subprojeto: " $O s$ Caminhos do Café no Paraná" ${ }^{3}$ a fim de

\footnotetext{
${ }^{2}$ No decorrer desta pesquisa - 1987 - o IPAC/Lda. lançou uma publicação semanal no Jornal Folha de Londrina, "Memória e Cotidiano", para estabelecer um contato direto com a população, registrar e divulgar informações a respeito da memória coletiva da região. Como produto desta pesquisa o IPAC/Lda. lançou duas publicações. Ver INVENTÁRIO E PROTEÇÃO DO ACERVO CULTURAL DE LONDRINA, Vila Casoni: retratos de um bairro londrinense. Londrina, UEL, 1988; Onde o bairro é a casa. UEL/ARU. Cadernos do Patrimônio Cultural, Série Estudos n.1, 1989. Vila Casoni: memória e cotidiano. Curitiba: MIS, Vídeo 14', 1989. Também cabe realçar que esta pesquisa subsidiou uma dissertação de mestrado Ver: MAIA, Deise. Abaixo da Linha: Casoni uma vila da cidade Londrina". Dissertação de Mestrado apresentada ao Departamento de Antropologia da Universidade de São Paulo, 1993.

${ }^{3}$ As várias ações elaboradas estão sendo desenvolvidas, tais como: Espaços e Marcas das sedes e casas de fazenda: a arquitetura de madeira: Rolândia-Pr.; Ribeirão Claro: Espacialização e Memória Ativa, 1989; o IPAC vai a escola do Heimtal, 1990; Os Signos de Nova Dantzig e a Memória
} 
descortinar os suportes materiais e as teias de relações sociais e seus significados para diversos grupamentos sociais.

Desta maneira, a escolha em trabalhar a questão do Patrimônio no Norte do Paraná permitiu ao mesmo tempo revelar aspectos importantes das relações com a ocupação da região e a economia do café e descobrir territórios que foram colonizados por diferentes grupos, os quais deixaram marcas impressas na paisagem e no modo de vida.

Atualmente, redefinidos na fisionomia $e$ relações sociais, as análises sobre estes locais proporcionaram, por um lado, o entendimento da construção de espaços e de sociabilidades específicas, por outro forneceram indicativos importantes acerca das experiências dos diferentes grupos étnicos e dos modos peculiares de existir socialmente na região.

A maneira de se registrar a memória coletiva da região difere daquela organizada por grupos hegemônicos que privilegiam "grandes acontecimentos" e personagens notáveis". O trabalho do IPAC, ao dar ênfase à história contada pelos personagens coadjuvantes do processo de formação do município de Londrina descortina micro-relações e espaços "intersticiais" criados no cotidiano, apesar de processos sociais mais amplos, exprimindo a história "circunstancial". Ao optar por este caminho os pesquisadores entendem estar interpretando redefinições de espaços e a sua lógica interna, revelando, assim, pistas para a compreensão da existência de diferentes modos de vida na cidade de Londrina e região.

\section{ESPAÇOS, MEMÓRIA E COTIDIANO}

Escolher o simbólico como objeto privilegiado de análise no norte do Paraná significa reconhecer, em primeiro lugar, a importância de um estudo dessa natureza, uma vez que grande parte das análises já elaboradas sobre a região destacam, sobretudo, aspectos ligados às relações de produção. Em segundo lugar, por se tratar de um território de ocupação recente em que os atores sociais ainda podem ser encontrados como testemunhas vivas desse processo.

Coletiva em Cambé, 1992 e o Cotidiano da Warta: o passado e o presente.
A contemporaneidade desse projeto de ocupação na região norteparanaense é responsável pelo surgimento de uma densidade de imagens, metáforas e alegorias no nível simbólico, produzidas para imprimirem uma identidade aos espaços, suas apropriações e usos no cotidiano do passado e do presente.

Enquanto que no Paraná "tradicional", formado pelo litoral, planalto de Curitiba e Campos Gerais, a memória coletiva ${ }^{4}$ tende a ser relacionada a edificações e monumentos, bem como registrada e traduzida de modo mais sistemático, no Paraná "moderno", "tudo ainda está por se fazer" como dizem os planejadores da cidade preocupados com o patrimônio ambiental urbano. Na verdade, muitos desses especialistas sentem-se aturdidos pela rapidez das transformações e pela fugacidade da paisagem urbana e arquitetônica, mais ainda, por não conseguirem se desvencilhar das linguagens estéticas e construtivas do tipo colonial - lusobrasileiro - presentes no Paraná "tradicional".

Por sua vez, os que se ocupam em sistematizar as narrativas acerca do Paraná "moderno", interpretando as vozes do passado que aí ainda se fazem presentes, arriscam-se em se deixar enredar nas armadilhas da reificação, reproduzindo as imagens, os mitos, as alegorias daqueles que almejam notabilizar a memória recente e, se possível, conferindo-lhe um sentido épico e heróico. Esses talvez estejam igualmente seduzidos pelas imagens já reconhecidas em regiões mais antigas, trazendo-as como referências para interpretar um legado cultural recente.

Desse modo, as experiências de pesquisa do IPAC/Lda. mostraram que as expressões como: "pioneiro", "pequena Londres", "cidade moderna", "capital mundial do café", "cidade de oposição", "eldorado", "terra prometida", "ouro verde",

\footnotetext{
${ }^{4}$ Pretende-se trabalhar o conceito de memória coletiva a partir do estudo clássico de Maurice Halbwachs, a saber: como um conjunto de significados sociais que não se confunde com a memória individual, mas exprime uma referência para a última. Este conceito, que está na origem de um debate que envolve sociblogos, historiadores e psicólogos abre uma perspectiva para se entender os cruzamentos entre memória pessoal e memória social, entre memória autobiográfica e história nacional. (HALBWACHS, Maurice. A memória coletiva. São Paulo: Vértice, 1990). O trabalho sobre "lembranças" de velhos acerca da cidade de São Paulo de Eclea Bosi também se reporta ao estudo clássico de HALBWACHS. Ver: BOSI, Eclea. Memória e sociedade: lembranças de velhos. São Paulo: T.A. Queiroz, 1983.
} 
"abaixo e acima da linha" entre outras, assumem significados de categorias nativas que permitem descortinar Londrina através de um possível campo de luta simbólica, expressando tensões originárias nas práticas sociais onde diferentes atores jogam infinitas partidas de uma contenda. ${ }^{5}$

Portanto, trabalhar com o simbólico implica também na identificação de tensões, antagonismos e complementaridade entre grupos de atores, considerando as representações "coladas" às práticas sociais ${ }^{6}$, tecendo uma "intriga" que articule a história circunstancial com a História (com H maiúsculo), esta compreendida como narrativa dos grandes acontecimentos. ${ }^{7}$

As cidades de colonização mais antiga são tradicionalmente palco para o imaginário da preservação, que se encontra presente, quer em iniciativas particulares de defesa do patrimônio, quer em propostas dos órgãos preservacionistas. Consideradas "históricas", essas cidades retratam cenários de acontecimentos passados e guardam as marcas da época que se expressam no traçado das ruas e nos aspectos arquitetônicos.

Os órgãos oficiais de defesa do patrimônio, geralmente consideram o edificado como fio condutor de estudo e como objeto de intervenções, adotando critérios de seleção históricos e/ou artísticos. Deste modo, a prática preservacionista

5 Alguns trabalhos sobre Londrina apontam a existência de expressões que compõem o imaginário da cidade. Sobre "cidade de oposição", ver: CESÁRIO, Ana Cleide Chiarotti. Poder e Partidos Políticos em uma cidade média brasileira, tese de doutorado, (mimeo). São Paulo, USP, 1986. Sobre "abaixo e acima da linha", ver: MAIA, Deise. "Abaixo da linha": Casoni, uma vila da "cidade londrina", dissertação de mestrado, (mimeo), São Paulo, USP, 1993. Sobre "Eldorado", ver: ARIAS NETO, José Miguel. O Eldorado: Londrina e o Norte do Paraná - 1930-1975, dissertação de Mestrado, (mimeo), São Paulo, USP, 1993.

${ }^{6} \mathrm{O}$ trabalho de José Guilherme Magnani aponta uma discussão fundamental a este respeito, ver: MAGNANI, José Guilherme Cantor. Discurso e Representação, ou De como os baloma de Kiriwina podem reencarnar-se nas atuais pesquisas. In: CARDOSO, Ruth Corrêa L. (Org.). A aventura antropológica: teoria e pesquisa. Rio de Janeiro: Paz e Terra, 1986, p.127-140.

${ }^{7}$ O sociólogo José de Souza Martins trabalha de modo muito atraente a história circunstancial no subúrbio. Ver: MARTINS, José de Souza. Subúrbio. Vida cotidiana e história no subúrbio da cidade de São Paulo: São Caetano, fim do Império ao fim da República Velha. São Paulo: HUCITEC; São Caetano do Sul: Prefeitura de São Caetano do Sul, 1992, $363 \mathrm{p}$. elege os bens culturais de valor excepcional, que são traduzidos ou pela história ou pela arquitetura. Em outros termos, as estratégias voltadas para a preservação ocupam-se do inventário e da preservação do edificado, concebido como importante na perspectiva da história oficial. Assim, propõe-se o tombamento, a restauração, a reutilização e a preservação de casas, rodoviárias, teatros, igrejas, escolas, e outros suportes materiais.

Estes critérios marcam a postura de uma política de preservação que privilegia e legitima a produção material de determinados grupos sociais, recomendando o seu uso. Na maioria das vezes, deixa de mostrar o envolvimento $\mathrm{e}$ as representações de novos personagens, com esses cenários, no presente, impedindo portanto, a revelação do patrimônio cultural em termos mais amplos, isto é, a evidência do edificado aliado às relações sociais e às manifestações simbólicas, na dinâmica entre espaço, tempo, uso e diferentes fatores sociais.

Em cidades de colonização recente, a exemplo de Londrina, algumas manifestações de segmentos da população têm trazido à cena discussões a respeito da questão do patrimônio e da preservação. $\mathrm{Na}$ verdade, o que se percebe, geralmente, é a tendência em transferir esse imaginário das cidades mais antigas - a partir dos "feitos históricos" e "fatos notáveis" para um processo pioneiro instaurado na região que deixou marcas, quer na paisagem urbana, quer no modo de vida que se manifestou, formando um patrimônio com características associadas ao desenvolvimento da cafeicultura.

Entretanto, a dificuldade está em delimitar os cenários, de modo a vê-los, como em cidades mais antigas, em função da "precariedade" da paisagem urbana, que se apresenta com feições constantemente renovadas. Neste sentido, as discussões que envolvem os bens culturais, em termos do edificado, deparam-se com a sua frágil durabilidade. As construções, tanto as de madeira quanto as de alvenaria, inclusive as mais suntuosas - embora algumas delas estejam presentes e reutilizadas -, em sua maioria, cedem lugar a arranha-céus exuberantes, anunciando uma modernização que transforma a organização do espaço e as relações sociais.

Cidades como Londrina podem se constituir em "locus" estratégico para a análise e relativização do ângulo de visão tradicional do 
patrimônio. Nesse sentido, o desafio teórico será o de acrescentar uma visão antropológica e sociológica às óticas da arquitetura e história, áreas que tradicionalmente trabalham com o patrimônio. Pretende-se, portanto, evidenciar o sentido de cultura presente na noção de patrimônio.

O conceito antropológico de cultura passa a ser, para este estudo, um referencial decisivo para a compreensão do patrimônio. Cultura compreendida de maneira como explica Durham:

"Todo comportamento bumano é artificial e não natural. $O$ bomem construiu, através de sistemas simbólicos, um ambiente artificial no qual vive e o qual está contimuamente transformando. A cultura é, propriamente esse movimento de criação, transmissão e reformulação desse ambiente artificial." 8

Como se observa através desta definição, a cultura, do ponto de vista antropológico, tem dois sentidos:

a)a cultura é o resultado da ação do homem sobre a natureza e a produção de um "ambiente artificial". Por este ponto de vista a cultura se confunde com "condições de vida" e todos os homens são seres culturais;

b)a cultura é também trabalho cultural uma vez que os homens operam através de sistemas simbólicos, criando e reformulando o ambiente artificial. É, portanto, "um valor" e uma avaliação que os homens fazem de seu próprio mundo.

Sendo assim, o patrimônio cultural poderá ser compreendido como simplesmente os suportes e símbolos culturais e, também, como os produtos de criação das obras de pensamento e obras de arte. ${ }^{9}$

A partir desses dois significados existentes na noção de cultura é que nos será possível não nos referirmos apenas aos conceitos de patrimônio histórico ou artístico, mas trabalharmos com a noção de patrimônio cultural:

a)como suportes materiais da cultura: patrimônio ambiental urbano (edifícios, monumentos, manchas e sítios urbanos);

\footnotetext{
${ }^{8}$ DURHAN, Eunice. Cultura, patrimônio e preservação. In: ARANTES. Antônio Augusto (Org.). Produzindo o Passado. São Paulo: Brasiliense, 1984.

${ }^{9}$ CHAUÍ, Marilena. Política cultural. Cultura política e patrimônio histórico. In: CUNHA, Maria Clementina Pereira (Org.) $\mathbf{O}$ direito à memória. Patrimônio Histórico e cidadania. São Paulo: DPH. 1992.
}

b)bens simbólicos: diferentes linguagens artísticas, tradições, representações sociais e o imaginário.

O modo como passamos a entender o patrimônio nos leva a inscrever a questão num contexto bastante abrangente, isto é, compreender o patrimônio cultural a partir de relações interpessoais, de modos de vida, redes de sociabilidade revelando a temática do cotidiano ${ }^{10}$ buscando, todavia, estabelecer relações desses acontecimentos "micros" com situações "estruturais" e de "longa duração".

Para isso, é importante "interpretar as interpretações" 11 de representantes de grupamentos sociais acerca dos seus padrões culturais, buscando compreender as representações aliadas às práticas sociais que traduzem "jeitos de ser $e$ de viver" através do que protagonistas da cidade dizem "sobre si e para si". Essa fala não é intimista, pois ao se expressarem estarão se referindo também aos espaços da cidade, aos valores e tradições, uma vez que são personagens sociais que constróem e dão significado ao lugar onde vivem, revelando a existência de muitas "Londrinas" dentro de Londrina.

$\mathrm{Se}$ as representações estão assentadas nas práticas sociais, isto é, relacionando-se ao trabalho, às trajetórias de vida, às práticas religiosas $\mathrm{e}$ políticas, a laços de interação e lazer, existe um outro território no campo simbólico que é de caráter mais difuso, coletivo e impreciso: o imaginário. Como sublinha Machado:
"imagens são construções simbólicas coletivas e, nesse sentido, elas estão na mesma esfera das representações. Mas isso não implica a possibilidade de se reduzir as imagens sobre a cidade às representações (coladas às práticas) que informam e orientam as condutas cotidianas. Pensar o imaginário, simplesmente e diretamente como uma constelação de representações, seria retirar do mesmo, completamente, em primeiro lugar, sua especificidade, reduzindo-o às representaçôes e, em segundo lugar, sua eficácia que é função corolária $e$ demonstração dessa especificidade.

\footnotetext{
${ }^{10}$ MAGNANI, José Guilherme Cantor. Inventário e proteção Cultural: o enfoque antropológico. Curitiba, (mímeo), 1985. É interessante, também, consultar a coletânea de ARANTES, Antônio Augusto (Org.). Produzindo o passado. Estratégias de comunicação do Patrimônio Cultural. São Paulo: Brasiliense, 1984.

${ }^{11}$ GEERTZ, Clifford. A interpretação das culturas. Rio de Janeiro: Zahar, 1978.
} 


\begin{abstract}
"Talvez possamos estabelecer a relação entre o imaginário e as representações a partir de uma metáfora porque, se por um lado, perde-se em precisão, por outro, ganba-se em clareqa, se é que a metáfora é adequada como me parece. Entendo que poderíamos pensar as relações sociais concretas que informam as práticas cotidianas como se fossem um dicionário e as imagens sociais como se fossem as bistórias construidas com as palauras desse dicionário.
\end{abstract}

"Estou sugerindo portanto, que o imaginário social e as representações sociais se diferenciam e se constituem em suas individualidades como estruturas narrativas distintas" 12 ..

Trabalhar o imaginário possibilita distinguir, através dos discursos, duas narrativas. A primeira, a linguagem das representações, isto é, como os atores usam de imagens que expressam suas experiências. Falar sobre "o trabalho duro dos primeiros tempos", do "lamaçal e da poeira vermelha", dos "ranchos de palmito" revela imagens vividas e sentidas através de suas práticas cotidianas do passado. Todavia, a narrativa do imaginário realça imagens diluídas e quase nunca vivenciadas pelos atores. Geralmente, são metáforas de significado genérico carregadas de valores que marcam territórios e distinções simbólicas conferindo feições à cidade e suas personagens. Quando os atores se referem ao "eldorado", à "terra prometida" ao "ouro verde", à "cidade dos pés vermelhos" è à "cidade moderna", entre outras expressões, muitas vezes, estão se apropriando de imagens genéricas nem sempre por eles produzidas. Embora esta apropriação implique num redimensionamento dessas imagens, esse processo se faz de modo muito semelhante ao de uma imagem refletida num espelho, sugerindo múltiplas percepções dependendo da superfície na qual se espelha e do lugar de onde se olha - podendo inclusive produzir ilusões na forma dessas imagens.

A análise dessas metáforas e alegorias permite descortinar como representantes de grupos sociais internalizam e exteriorizam idéias acerca da cidade no passado e no presente, sinalizando os lugares por eles ocupados no cenário urbano e fornecendo

\footnotetext{
${ }^{12}$ MACHADO, Luiz Antônio. O Imaginário Urbano e as representações sociais. (Conferência proferida no $\Pi^{\circ}$ Debate Nacional: Patrimônio, Preservação e Imaginário Urbano. Londrina: IPAC/LDA, 1982).
}

pistas sobre quem elabora os símbolos e quem se apropria dos ganhos inerentes ao capital cultural.

A elaboração de metáforas e alegorias deve ser compreendida no Norte Novo do Paraná considerando-se que se trata de uma região de colonização recente e para onde acorreu intenso fluxo migratório proveniente de várias regiões do país, da Europa e Oriente. Esta colonização, marcada por um processo de ocupação induzida, com forte apelo propagandístico, atraiu para Londrina - a cidade sede do projeto empresarial $e$ imobiliário da CTNP ${ }^{13}$ - atores sociais de várias origens, a saber: nacionais - paulistas, mineiros, nordestinos e paranaenses do sul - e estrangeiros ingleses, alemães, italianos, poloneses, ucranianos, búlgaros, espanhóis, japoneses e árabes, criando, numa pequena fração de tempo, uma população heterogênea nas suas origens. Desse modo, compreende-se o porquê da existência de um farto material de propaganda da Companhia colonizadora enaltecendo as qualidades do lugar: "terras salubérrimas", "aqui, saúvas não há", "títulos de posse da terra confiáveis e a certeza do lucro". Tratava-se de uma estratégia de elaboração de "slogans" capazes de definir em vários atores, dos mais diferentes pontos do Brasil e do exterior, projetos migratórios convergentes. Eram "chamadas" que antecipavam um imaginário do migrante sobre a cidade e região.

Esses migrantes, portadores de idéias, valores e tradições de seus lugares de origem, ao chegarem em Londrina, iniciaram um processo de redefinição, não apenas do modo de viver, mas também de reelaboração de suas identidades ${ }^{14}$, isto é, da noção

\footnotetext{
${ }^{13}$ Cabe considerar que na região norte paranaense ocorreu um processo de ocupação induzido pela Companhia de Terras Norte do Paraná-CTNP. Este empreendimento colonizador constituiu um sistema, organizando uma frente pioneira - de caráter empresarial imobiliário - juntamente com a construção de uma ferrovia e vinculado à economia do café. Além da demarcação do meio rural a empresa encetou um plano de urbanização no "norte novo" no final dos anos 20 e início dos anos 30. Em Londrina a CNTP projetou a área urbana,

deixando as suas marcas impressas na paisagem e no modo de vida dos seus moradores.

${ }^{14}$ Uma referência importante a respeito do conceito de identidade relacionado à estrutura social é o trabalho de CARDOSO DE OLIVEIRA, Roberto. Identidade e estrutura social. In: Anuário Antropológico 78, Rio de Janeiro, 1980, p.243-263.; Outra discussão a destacar sobre este tema é a de: DA MATTA, Roberto. Carnavais, malandros e heróis: por uma sociologia do dilema brasileiro. Rio de Janeiro: Zahar, 1979.
} 
anterior de pertencimento ${ }^{15}$ que lhes permitia reconhecer as suas semelhanças, bem como suas diferenças.

A partir de suas trajetórias, das novas experiências e práticas sociais é que as identidades de origem serão reconstruídas, incorporando o imaginário da cidade criado pela CTNP e pelos primeiros que aí chegaram.

Com o desenvolvimento de Londrina, uma nova heterogeneidade se soma à anterior, a organização em camadas sociais acompanhadas da construção de vários espaços menores dentro da cidade: o centro, as vilas, os patrimônios e, mais tarde, os bairros, os jardins, os conjuntos habitacionais.

Quando os atores sociais se referem a essas categorias, pressupõe-se que no nível de suas representações e de seu imaginário, há mais do que as lógicas do rural/urbano e do centro/periferia. Novamente em Londrina, produziu-se uma série de imagens e significados que oferecem um sentido especial a essas categorias, aparentemente adotadas do jargão técnico e da linguagem da planificação urbana, mas que na verdade têm os seus sentidos emanados das ações sociais, constituindo-se em novas representações e num novo imaginário que traduzem a cidade de hoje.

É assim que se concebem: o centro, muitas vezes, identificado com o "espigão", com a noção "acima da linha"; a vila, cuja origem está na gleba urbana relacionada à expressão "abaixo da linha"; o patrimônio, categoria originária do planejamento da CTNP, hoje definido como "lugarejo" e "cidadinha"; os jardins sob a ótica do planejamento urbano moderno, hoje lugares da "riqueza" e da "pobreza", e os conjuntos habitacionais (da zona norte) atualmente se constituindo em dezenas e sendo, genericamente, chamados de "cinco conjuntos".

Paralelamente a essas expressões existem outras que demarcam fronteiras, territórios, passagens e monumentos, tais como: "vazios",

${ }^{15}$ A noção de pertencimento é tratada de modo interessante na discussão de: LA FONT, Hubert. Turma de jovens. In: ARIÈS, Philipe e BEJIN, André. (Orgs.) Sexualidades ocidentais. São Paulo: Brasiliense, 1982. Deve-se também considerar os trabalhos de Geralda Seyferth a exemplo de: SEYFERTH, Geralda. A colonização alemã no vale do Itajaí-Mirim. Porto Alegre: Movimento, 1974; Ruben Oliven tem apresentado discussões a esse respeito, ver: OLIVEN, Ruben George. A parte e o todo. A diversidade cultural do Brasil-nação. Petrópolis: Vozes, 1992. "via leste-oeste", "via expressa" (Av. Dez de Dezembro), "BR-369", "fundo de vales", "perobal" (Campus Universitário), "shopping", (Catuaî), "a nova rodoviária" (projeto de Oscar Niemayer), a "antiga rodoviária" (projeto de Vila Nova Artigas, tombada pelo Patrimônio Estadual e abrigando, após restauração, o Museu de Arte de Londrina/MAL), a "ferroviária" (após reciclagem, o museu Histórico de Londrina "Pe. Carlos Weiss"), o "Bosque" (logradouro central com alguns exemplares de mata nativa), o "Terminal Rodoviário Urbano" (construído no antigo leito da ferrovia), o "calçadão" (antiga Av. Paraná), a "Higienópolis" (antiga rua das residências dos fazendeiros), a "Duque" (Avenida Duque de Caxias, antiga "Rua Heimtal", com lojas que lembram os empórios e armazéns que compuseram a fisionomia da Londrina do passado).

Como se observa, os pesquisadores levam em conta os espaços apropriados e ocupados sob a ótica do cotidiano (este último, muitas vezes considerado "banal") no passado e no presente, tendo um arcabouço teórico intrigante para os estudiosos de Ciências Sociais, uma vez que existem complexidades para explicar as articulações existentes entre o espaço, as representações, o imaginário e a identidade, assim como descerrar essa cortina, trazendo à cena o palco do simbólico. Mais ainda, procuram estabelecer um diálogo com outras áreas do conhecimento (Arquitetura, História, Geografia, entre outras), propiciando mais uma interpretação da cidade dentre outras já existentes.

Um trabalho como este caracteriza-se pela sua interdisciplinaridade, uma vez que é desenvolvido por profissionais das áreas de Antropologia, Ciência Política e Sociologia, insinuando-se como uma dentre as possíveis "leituras" a respeito da cidade e seus padrões culturais, com a intenção de provocar inquietude em outros interlocutores, tais como: historiadores, arquitetos, geógrafos e filósofos.

As informações empíricas permitem, através de estudos microscópicos e detalhados, polemizar categorias teóricas das Ciências Sociais, propondo revisões conceituais, buscando dessacralizar idéias já consagradas que norteiam a formulação de políticas públicas referentes ao planejamento da cidade e à preservação do patrimônio ambiental urbano. 
Mais ainda, busca-se estabelecer laços de envolvimento e alianças entre pesquisadores e personagens sociais num processo dinâmico de "produção" da memória coletiva, através do qual valores e tradições são identificados compreendendo-se a noção de pertencimento, bem como sugerindo-se a importância do exercício da cidadania cultural. Esta última entendida como o direito ao registro da memória e ao reconhecimento do patrimônio cultural. ${ }^{16}$

A investigação de campo e os procedimentos metodológicos que contemplam tanto o estudo do cotidiano quanto a utilização da história oral constituem desafios que colocam os pesquisadores do IPAC/Lda. diante das dificuldades em articular categorias nativas ${ }^{17}$ aos eixos de análise. Mais ainda, em compreender que, entre a sua interpretação e a do ator social, existem: a fala, o discurso, as ações e as representações sociais; enfim o reconhecimento que no campo da sociologia/antropologia o principal objeto são as relações sociais, pois, nesta área o relevante é o ponto de vista compreensivo em que se procura revelar o significado das interações produzidas pelos próprios homens. ${ }^{18}$

\section{REFERÊNCIAS BIBLIOGRÁFICAS}

ARIAS NETO, José Miguel. O Eldorado: Londrina e o Norte do Paraná - 1930-1975. Dissertação de Mestrado, (mimeo). São Paulo: USP, 1993.

ARIÈS, Philipe et al. (Org.). Sexualidades Ocidentais. São Paulo: Brasiliense, 1982.

BOSI, Ecléa. Memória e sociedade: Lembranças de Velhos. São Paulo: T. A. Queiroz, 1983.

\footnotetext{
${ }^{16}$ Para uma maior compreensão da noção de cidadania cultural, ver: PAOLI, Maria Célia. Memória, História e cidadania: o Direito ao passado, pp. 25 a 28, In: Secretaria Municipal de Cultura. Departamento do Patrimônio Histórico. O Direito à Memória: Patrimônio histórico e cidadania. DPH. São Paulo. 1992; CUNHA, Maria Clementina Pereira. Patrimônio Histórico e cidadania: uma discussão necessária. Ibidem, pp. 09 a 11.

${ }^{17}$ A este respeito Gilberto Velho mostra que o investigador deve estar atento quer à especificidade de áreas ou domínios de uma sociedade quer ao modo como indivíduos do universo investigado(os próprio nativos) percebem e definem tais domínios. Assim o autor sublinha que o pesquisador não irá analisar a sociedade somente a partir do próprio sistema classificatório nativo. Nesse sentido, as Ciências Sociais desenvolveram conceitos e instrumentos de trabalho que se entrecruzam a percepções e experiências de diferentes grupos. Ver. VELHO, Gilberto. Individualismo e cultura. Notas para uma antropologia da sociedade contemporânea. Rio de Janeiro: Zahar, 1981.

${ }^{18}$ WEBER, Max. Ação e relação social. In: Weber, Coleção Grandes Cientistas Sociais. São Paulo: Ática, 1979
}

CARDOSO DE OLIVEIRA, Roberto. Identidade e Estrutura Social. In: Anuário Antropológico 78. Rio de Janeiro: 1980. p.243-263.

CESÁRIO, Ana Cleide C. et al. Onde o Bairro é a Casa. Londrina: CONCITEC/UEL, 1989.

Surge a cidade "londrina". In: Poder e Partidos Políticos em uma cidade Média Brasileira: Um Estudo de Poder Local. Londrina-Pr. Tese de Doutorado apresentada ao Departamento da Faculdade de Filosofia, Letras e Ciências Humanas da Universidade de São Paulo, 1986.

CHAUÍ, Marilena. Política Cultural. Cultura Política e Patrimônio Histórico. In: CUNHA, Maria Clementina P. (Org.). O Direito à Memória. Patrimônio Histórico e cidadania. São Paulo: DPH. 1992.

DA MATTA, Roberto. Carnavais, Malandros e

Heróis: por uma Sociologia do dilema brasileiro. Rio de Janeiro: Zahar, 1979.

DURHAN, Eunice R. Cultura, Patrimônio e Preservação. In: ARANTES, Antônio A. (Org.)

Produzindo o Passado. São Paulo: Brasiliense, 1984. GEERTZ, Clifford. A interpretação das Culturas. Rio de Janeiro: Zahar, 1973.

HALBWACHS, Maurice. A Memória Coletiva. São Paulo: Vértice, 1990.

MACHADO, Luiz A. O imaginário urbano e as representações sociais. (Conferência proferida no $\Pi^{\circ}$ Debate Nacional: Patrimônio, Preservação e Imaginário Urbano. Londrina: IPAC/Lda, 1982).

MAGNANI, José G. Inventário e Proteção do Acervo Cultural: o enfoque antropológico. Curitiba: mimeo, 1985.

Discurso e Representação, ou De como os Baloma de Kiriwina podem reencarnar-se nas atuais pesquisas. In: CARDOSO, Ruth C. (Org.). A aventura antropológica: Teoria e Pesquisa. Rio de Janeiro: Paz e Terra, 1986. p. 127-140.

MAIA, Deise. Abaixo da Linha: Casoni, uma vila da "cidade Londrina". Dissertação de Mestrado, apresentada ao Departamento de Antropologia da Universidade de São Paulo-USP, 1993.

MARTINS, José de Souza. Subúrbio. Vida cotidiana e história no subúrbio da cidade de São Paulo: São Caetano, fim do Império ao fim da República Velha. São Paulo: HUCITEC, 1992. 363p.

OLIVEN, Ruben George. A parte e o todo. A diversidade cultural no Brasil Nação. Petrópolis: Vozes, 1992.

SEYFERTH, Geralda. A colonização alemã no vale do Itajaí-Mirim. Porto Alegre: Movimento, 1974.

VELHO, Gilberto. Individualismo e Cultura: notas para uma Antropologia da sociedade contemporânea. Rio de Janeiro: Zahar, 1981.

WEBER, Max. Ação e Relação Social. In: Weber. Coleção Grandes Cientistas Sociais. São Paulo: Ática, 1979. 